\title{
Surface Roughness Measurement of Casted Parts after Abrasive Blasting Processing
}

\author{
Viktor Sychuk $^{1}$, Oleg Zabolotnyi ${ }^{2}$, Dmytro Somov ${ }^{3}$, \\ Galina Golodyuk ${ }^{4}$, Andrii Slabkyi ${ }^{5}$ \\ \{svamator@gmail.com ${ }^{1}$, volynasi@gmail.com ${ }^{2}$, somovd@ rambler.ru ${ }^{3}$ \} \\ Lutsk National Technical University, Lutsk, Volyn region, zip code 43018, Ukraine
}

\begin{abstract}
This scientific paper was devoted to estimate roughness parameter of processed casted parts surfaces after abrasive blasting. It was offered to apply abrasive blasting processing, instead of shot blasting, of internal surface of water meter manufactured by molding with the purpose to increase productivity of the surface processing. There were shown roughness measurement results of experimental studies of processed surfaces using different technological regimes. It was shown an easy and simple way how to measure roughness using digital images of scanned processed surfaces and analyzing them in Gwyddion v.2.41 software. It was also introduced a formula which predict roughness of treated surface after abrasive blasting processing.
\end{abstract}

Keywords: roughness, abrasive blasting processing, processed surface.

\section{Introduction}

Increasing the efficiency of machining parts to provide the specified characteristics is an extremely important task of machine-building enterprises. Solving and researching this issue will significantly increase the processing efficiency, reduce the cost of manufacturing parts, and promote scientific development in this field of the national economy.

The processing of foundry body parts currently does not fully meet the requirements of modern machine-building enterprises, which usually use the classic methods of processing, which in turn in the current market conditions are not productive and costeffective.

\section{$2 \quad$ Literature Review}

Abrasive blasting is a modern, progressive method of processing, which is becoming more and more relevant in the technological processes of processing various parts [1]. Besides authors of this scientific paper introduced an idea and realization of increas- 
ing productivity of abrasive blasting processing of surfaces. Good results were obtained because of designing a new assembled abrasive jet nozzle and researching a special technology of its application [2], [3], [4].

The result of mentioned above treatment is a surface with defined geometrical properties where roughness is the most important for us. In most cases it is rather complicated to measure roughness especially if we want to get accurate calculated parameter of the whole area of the surface. That's why authors of this article introduce easier method how to estimate roughness of processed surfaces after abrasive blasting treatment.

Having read information about Gwyddion software [5], [6] we decided to use it in our investigation to define roughness.

\section{Research Methodology}

With the purpose to implement our ideas [2], [3], [4] we decided to determine optimal technological regimes of abrasive blasting while processing of the internal surface of the water meter KVB-10 (see Figure 1).

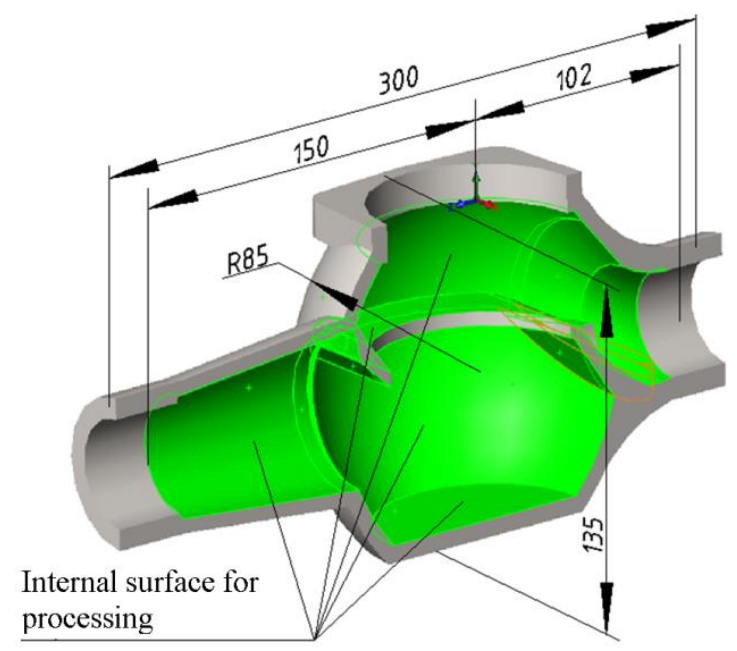

Fig. 1. General view of the body of the water meter KVB-10 with a chosen internal surface for processing (section).

So, according to the basic technological process the operation is shot blasting. This operation is necessary for processing of the internal surfaces of the water meter KVB10 to eliminate flows on foundry parts, rust, burnt-on. These defects of internal surfaces are very dangerous for the functioning of the water meter, because water that flow through the water meter, after some time, can erase these growths on the internal surface and they tend to accumulate and plug up the water flow, or lead to jamming of the rotary impeller, which calculates the volume of used water. 
In order to achieve maximum productivity in processing of this part of the body of the water meter, the idea was to replace the shot blasting process with abrasive blasting as more progressive and productive.

Experimental abrasive blasting processing of internal surfaces of the water meter KVB-10 consists in the application of various variables of technological parameters such as: fractional size of abrasive particles, the pressure of the mixture of the main flow of abrasive particles and air, the time of surface processing. During the experiment, the unprocessed internal surface of the water meter body was cut into 20 separate pieces with the purpose to process them using different modes of treatment.

A description of carrying out one of a series of experiments on the piece's surface is shown below:

1. Unprocessed surface is presented in Figure 2.

As can be seen from Figure 2, the surface contains flows and burns from casting and corrosion marks. To ensure the performance of parts in general these surface defects must be removed. It is worth noting that a blind hole is drilled on the surface, which serves as a reference point for the experimental area of the surface.

2. Surface was subjected to the following technological parameters of abrasive blasting processing:

- fractional size of abrasive - river sand with a predominant content of fractions of the size from $0,1 \mathrm{~mm}$ to $0,2 \mathrm{~mm}$;

- processing time - 15 seconds of abrasive blasting processing of the surface;

- pressure of the mixture of the main flow of air with abrasive - 0,7 MPa.

3. After the abrasive blasting processing it was obtained a purified surface, which is shown in Figure 3.

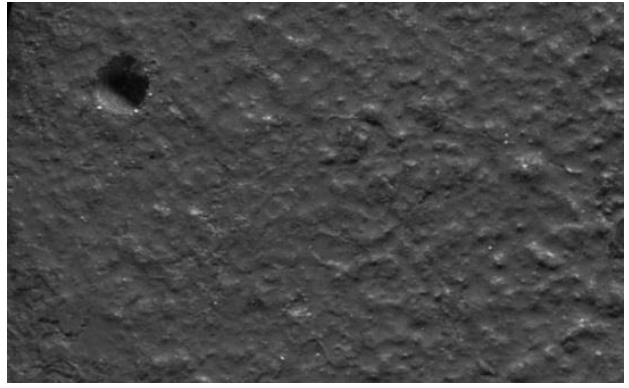

Fig. 2. Unprocessed internal surface of the water meter KVB-10 body.

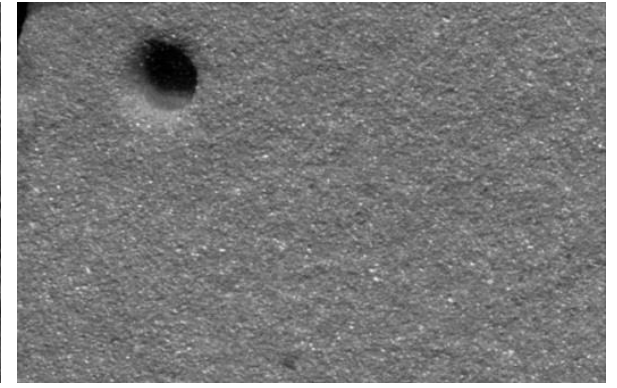

Fig. 3. Surface after abrasive blasting processing.

4. The next stage in the study of the surface was the analysis of roughness parameters before and after abrasive blasting processing.

After providing processing, surfaces were scanned to get digital images [7], [8], [9]. So, received images, scanned with a resolution of 25 million pixels $/ \mathrm{cm}^{2}$, of a surface before and after processing, were edited to obtain a square test area of $10 \times 10 \mathrm{~mm}$ which is at a definite location relative to the blind hole which is placed on the test 
surface. The image of the unprocessed and processed area of the surface is shown in Figure 4 and Figure 5 respectively.

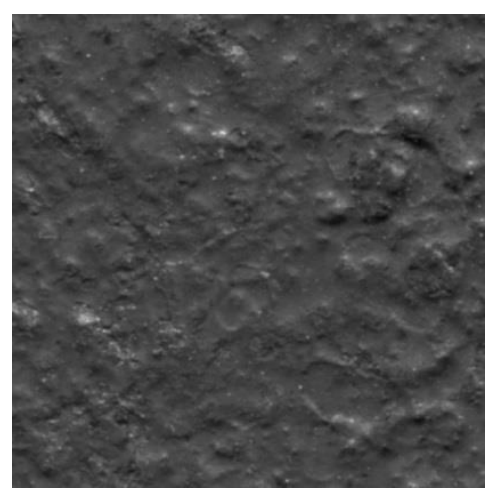

Fig. 4. Unprocessed area with the size of $10 \times 10 \mathrm{~mm}$ of a surface.

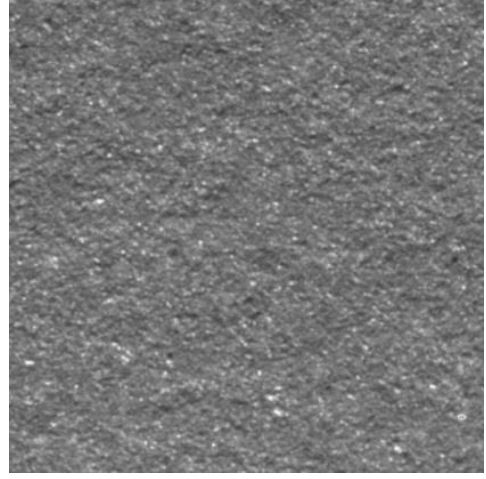

Fig. 5. Processed area with the size of $10 \times 10 \mathrm{~mm}$ of a surface.

Visually we can evaluate the above areas of surfaces and conclude that the elimination of flows, burns and corrosion marks has fully occurred.

For accurate determination of the surface roughness, Gwyddion v.2.41 software was used to analyze the digital images of certain surfaces. For the analysis of roughness, the following image parameters were used:

- file format - JPEG;

- the image size - 10 x 10 mm or 5000 x 5000 pixels;

- image palette - black and white with shades of gray.

The window of Gwyddion v.2.41 software with the analyzed image of the area 10x10mm of the unprocessed surface is shown in Figure 6.

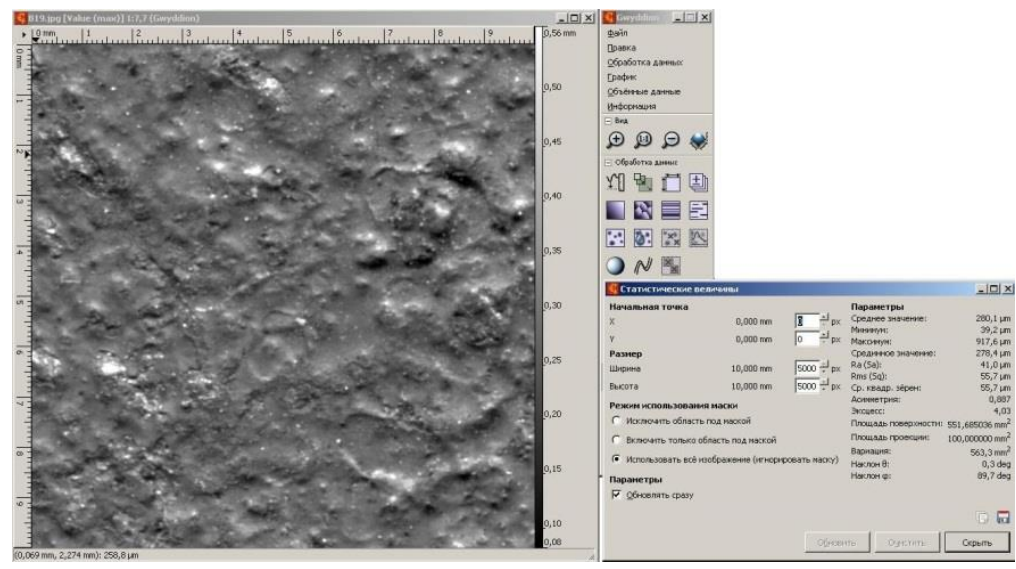

Fig. 6. The Gwyddion v.2.41 software interface with the analyzed image of the area $10 \times 10 \mathrm{~mm}$ of unprocessed surface. 
The used software analyzes the image and determines the geometric height between the lightest and darkest pixel of the image corresponding to the geometric height between the highest peak and the deepest cavity of the test surface of the part. From Figure 6 it is clear that after the automatic calibration (eliminating scan defects) the image height between the darkest and lightest pixels is equal to $0.56-0.08=0.48$ $\mathrm{mm}$. Then, after the automatic statistical analysis of roughness with the parameter Ra of the entire surface area of 10 × $10 \mathrm{~mm}$, the value Ra $41 \mu \mathrm{m}$ was obtained, which does not satisfy the requirements of the finished component, which contains this surface, so it is subject to mandatory processing, in our case, abrasive blasting processing.

For the analysis of the area of the processed surface a more precise definition of roughness was made. For the maximum correct input of the height adjustment parameter between the highest peak and the lowest cavity, three roughness measurements were carried out on each of the sections on the profilographer-profilometer model 202 of "Caliber" plant (see Figure 7). This measuring gauge has undergone a modernization to connect it to a personal computer with the ability to real-time, in the program PowerGraph, building a profile of measuring part with the ability to assess the geometric dimensions of all oscillations of the measuring probe.

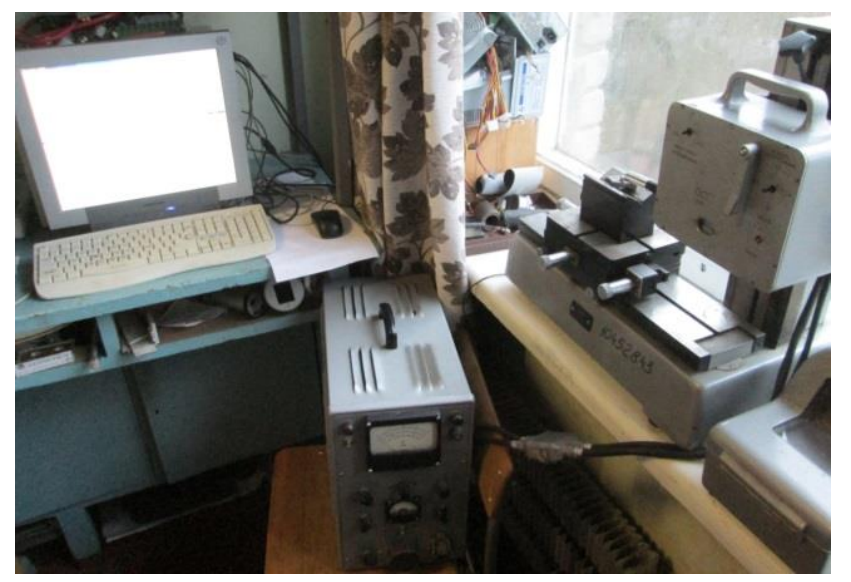

Fig. 7. The modernized profilographer-profilometer model 202 of "Caliber" plant.

Obtained profilograms of the three lines are shown in Figure 8, Figure 9, Figure 10, respectively. Analyzing three profilograms of different intervals of the area, taking into account the geometric inequality of the shape of the surface, it was determined that the averaged statistical value of the height between the highest peak and the lowest cavity is $93 \mu \mathrm{m}$. So, we applied the found value for analyzing the roughness of the area of the surface in the software Gwyddion v.2.41. Image parameters are similar to those of the unprocessed surface, ie:

- file format - JPEG;

- the image size is $10 \times 10 \mathrm{~mm}$ or $5000 \times 5000$ pixels;

- image palette - black and white with shades of gray. 


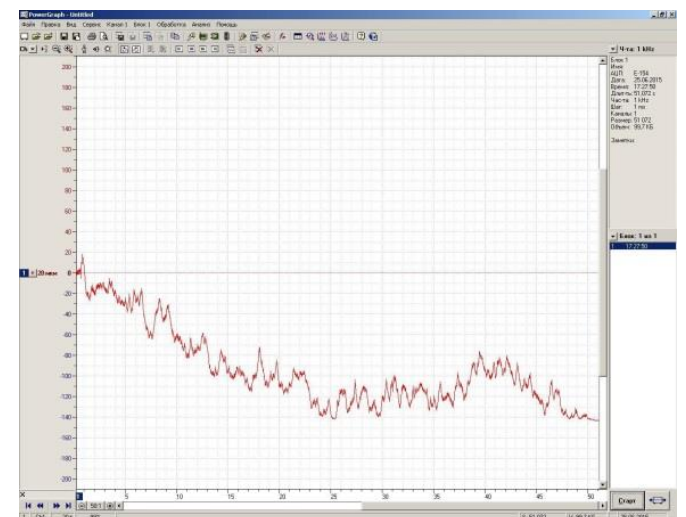

Fig. 8. Profilogram of the first line on the area of the processed surface.

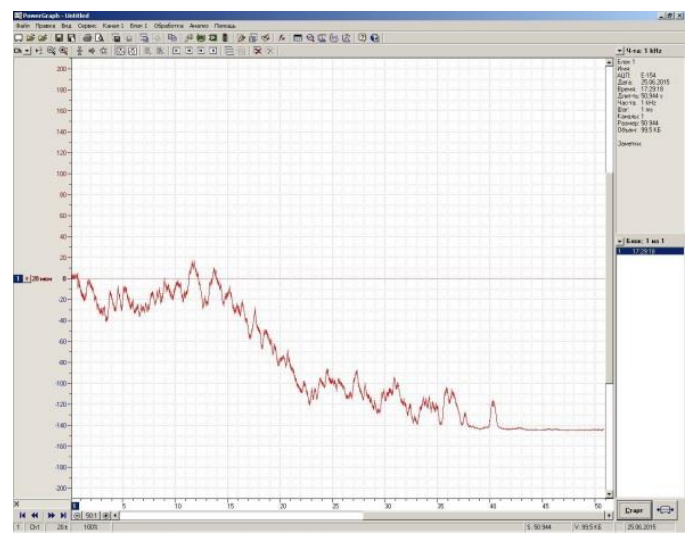

Fig. 9. Prophilogram of the second line on the area of the processed surface.

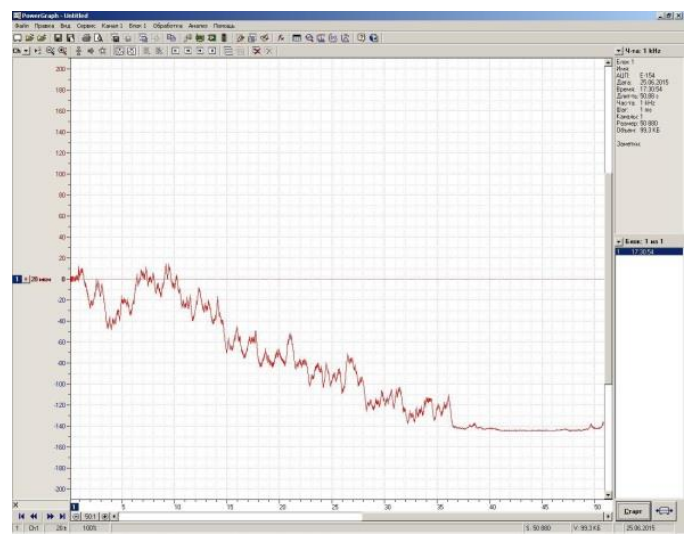

Fig. 10. Profilogram of the third line on the area of the processed surface. 
So the window of the Gwyddion v.2.41 program with the analyzed image of the area $10 \times 10 \mathrm{~mm}$ of the processed surface is shown in Figure 11.

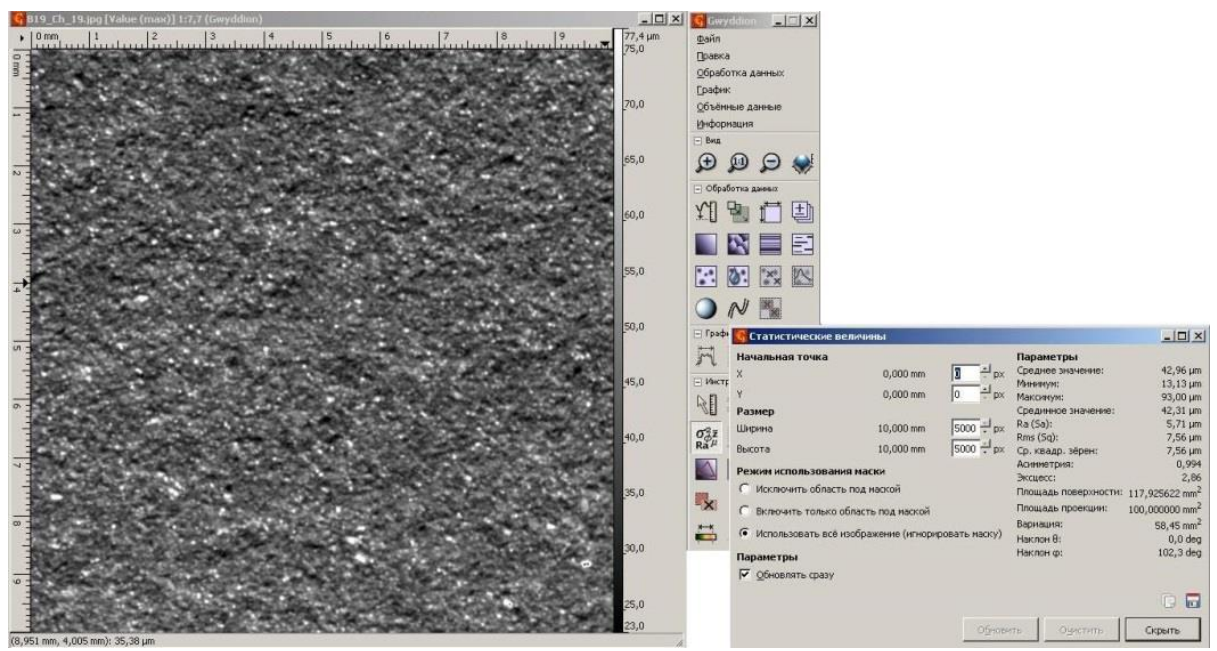

Fig. 11. The interface of Gwyddion v.2.41 software with the analyzed image of the area $10 \mathrm{x} 10 \mathrm{~mm}$ of the processed surface.

Figure 11 shows that after an automatic calibration (eliminating scan defects), the image height between the darkest and lightest pixels is $77.4-23.0=54.4 \mu \mathrm{m}$.

Then, after an automatic statistical analysis of the roughness according Ra parameter of the entire surface area of $10 \times 10 \mathrm{~mm}$, the value $\mathrm{Ra}=5.71 \mu \mathrm{m}$ was obtained, which completely satisfies the roughness parameter of the finished component.

Similarly, all other necessary experiments were conducted on the study of 20 other sections of the surface of the body of the water meter with different technological parameters of the abrasive blasting processing.

After obtaining practical results and using theoretical parameters it was derived a formula [10]:

$$
R a=2,358 \cdot 10^{-8} \cdot d_{\text {абраз }}^{6,6299(1-0,9868 \lg P-0,32 \lg t)} \cdot P^{8,4736} \cdot t^{2,7566}
$$

where $d_{\text {абраз }}$ - the size of the abrasive fraction, $\mathrm{mm}$;

$P$ - air pressure of the main flow, bar;

$t$ - time of abrasive jet processing, sec.

Using shown above formula (1) we can predict roughness of a surface after abrasive blasting processing varying with such parameters as size of abrasive fraction, air pressure of the working flow and a time of processing of a surface area. 


\section{$4 \quad$ Results}

Table 1 shows results of processing of 20 areas of the water meter internal surface by abrasive blasting processing under various technological regimes and using the method described above were obtained roughness indexes of surface.

Table 1. Results of experimental studies of abrasive blasting processing.

\begin{tabular}{|c|c|c|c|c|c|}
\hline № & $\begin{array}{c}\text { Air pressure } \\
\text { of the main } \\
\text { flow, MPa }\end{array}$ & $\begin{array}{c}\text { Pro- } \\
\text { cessing } \\
\text { time, } \\
\text { seconds }\end{array}$ & $\begin{array}{c}\text { Prevailing fractional } \\
\text { size of abrasive parti- } \\
\text { cles, mm }\end{array}$ & $\begin{array}{c}\text { Roughness } \\
\text { Ra of the } \\
\text { processed } \\
\text { surface, } \\
\mu \mathrm{m}\end{array}$ & $\begin{array}{c}\text { Roughness } \\
\text { Ra of the } \\
\text { unprocessed } \\
\text { surface area, } \\
\mu \mathrm{m}\end{array}$ \\
\hline 1 & 0,6 & 5 & from 0,2 to 0,315 & 24,8 & 43,2 \\
\hline 2 & 0,65 & 5 & from 0,2 to 0,315 & 15,6 & 40,3 \\
\hline 3 & 0,7 & 5 & from 0,2 to 0,315 & 14,3 & 39,6 \\
\hline 4 & 0,55 & 5 & from 0,2 to 0,315 & 19,9 & 48,3 \\
\hline 5 & 0,5 & 5 & from 0,2 to 0,315 & 9,1 & 49,7 \\
\hline 6 & 0,6 & 15 & from 0,2 to 0,315 & 5,6 & 37,8 \\
\hline 7 & 0,65 & 15 & from 0,2 to 0,315 & 6,6 & 32,2 \\
\hline 8 & 0,7 & 15 & from 0,2 to 0,315 & 6,6 & 68 \\
\hline 9 & 0,55 & 15 & from 0,2 to 0,315 & 8 & 55,1 \\
\hline 10 & 0,5 & 15 & from 0,2 to 0,315 & 7,1 & 46 \\
\hline 11 & 0,6 & 5 & from 0,1 to 0,2 & 13,5 & 43 \\
\hline 12 & 0,65 & 5 & from 0,1 to 0,2 & 13 & 42,1 \\
\hline 13 & 0,7 & 5 & from 0,1 to 0,2 & 10,7 & 34,4 \\
\hline 14 & 0,55 & 5 & from 0,1 to 0,2 & 10,5 & 33,5 \\
\hline 15 & 0,5 & 5 & from 0,1 to 0,2 & 7,8 & 39,5 \\
\hline 16 & 0,6 & 15 & from 0,1 to 0,2 & 11,1 & 32,8 \\
\hline 17 & 0,65 & 15 & from 0,1 to 0,2 & 7,6 & 42 \\
\hline 18 & 0,7 & 15 & from 0,1 to 0,2 & 8,6 & 41 \\
\hline 19 & 0,55 & 15 & from 0,1 to 0,2 & 12,8 & 39,7 \\
\hline 20 & 0,5 & 15 & from 0,1 to 0,2 & 10,7 & 43 \\
\hline
\end{tabular}

According to the manufacturing process, the production of the part of KVB-10 water meter during the control operation on checking the absence of flows, rust and burns must ensure roughness of the surface $\mathrm{Rz} 40$ which corresponding to an equivalent not greater than $\mathrm{Ra} 12.5$.

Analyzing table 1, this parameter of roughness is provided under the regimes used in the investigations at ordinal numbers $5,6,7,8,9,10,13,14,15,16,17,18,20$. As a result, in an experimental study, it was found that abrasive blasting processing of the internal surface of the water meter made from gray cast iron CЧ 20 (SCH20) made by casting, it is expedient to carry out using abrasive fractional sizes from $0.1 \mathrm{~mm}$ to 0.2 
$\mathrm{mm}$ and during processing time of 5 seconds. These modes are the most rational and provide the requirements of roughness to the surface of this part.

\section{Conclusions}

This article showed that it is possible to estimate roughness of the surface using a simple method mentioned above. This method also was justified with results obtained using formula (1), that's why it could be recommended for practical use.

This method also have limitations which means that we can estimate roughness only on relatively plain areas of a surface. The further investigations will be devoted to define roughness of non-plain surfaces with the use of 3D scanning technology.

\section{References}

[1] Provolotskyj A.: Abrasive-Jet Treatment of Machine Parts. Tehnika, Kyiv (1989)

[2] Sychuk V., Zabolotnyi O., Somov D.: Technology of Effective Abrasive Jet Machining of Parts Surfaces. In: Ivanov V. et al. (eds) Advances in Design, Simulation and Manufacturing. DSMIE 2018. Lecture Notes in Mechanical Engineering. Springer, Cham. https://doi.org/10.1007/978-3-319-93587-4_18 (2018)

[3] Sychuk, V., Zabolotnyi, O., McMillan, A.: Developing New Design and Investigating Porous Nozzles for Abrasive Jet Machine. Powder Metallurgy and Metal Ceramics. Vol. 910 (53), pp. 600-605. https://doi.org/10.1007/s11106-015-9655-1 (2015)

[4] Sychuk, V., Zabolotnyi, O., Golodjuk, R., Koljadunskyj, M.: Assembled Nozzle for Abrasive Jet Machines. Patent of Ukraine №104492 (2016)

[5] Nečas, D., Klapetek, P.: Gwyddion: An Open-Source Software for SPM Data Analysis. Open Physics. Vol. 10, Issue 1, pp. 181-188. https://doi.org/10.2478/s11534-011-0096-2 (2011)

[6] Klapetek, P.: Quantitative Data Processing in Scanning Probe Microscopy: SPM Applications for Nanometrology. Micro and Nano Technologies. William Andrew (2012)

[7] Pratt, W.: Digital Image Processing. Wiley-Interscience, New York (1978)

[8] Putjatin, E., Averin, S.: Processing of Images in Robotics, Mashinostroenie, Moscow (1990)

[9] Stas, O., Gavriljuk, V.: Computer Research Methods in the Metallographic Analysis. Methods of Research and Quality Control of Metals. Vol. 1-2, pp. 48-52 (2000)

[10] Sychuk, V.: Improving the Effectiveness of the Surface Treatment Technology of Casting Parts by Abrasive-Jet Processing. PL-NTU Cross-Border Experience Exchange. Vol. 3, pp. 55-72 (2015) 